\title{
The relation between low carbohydrate diet score and psychological disorders among Iranian adults
}

\author{
Zohreh Sadat Sangsefidi ${ }^{1,2}$, Amin Salehi-Abarghouei ${ }^{1,2}$, Zahra Sadat Sangsefidi ${ }^{3}$, Masoud Mirzaei \\ and Mahdieh Hosseinzadeh ${ }^{1,2^{*}}$
}

\begin{abstract}
Background: Since evidence regarding to low carbohydrate diet (LCD) and psychiatric disorders is little and controversial, this study aimed to assess relation between LCD score and psychological disorders including depression, anxiety, and stress among a large representative sample of Iranian adult population in Yazd city, Iran.

Methods: This cross-sectional analysis was conducted on data of 7165 persons who participated in the recruitment phase of Yazd Health Study (YaHS) and Taghzieh Mardom-e-Yazd (TAMIZ) study. Dietary intakes were evaluated by a validated semi-quantitative food frequency questionnaire. LCD score was calculated for each person according to summing up assigned scores to deciles of percentages of energy from macronutrients. Assessment of psychological disorders was also conducted by the validated Iranian version of depression, anxiety and stress scale questionnaire (DASS 21). Eventually, association between adherence to LCD and psychological disorders was evaluated via logistic regression.
\end{abstract}

Results: After adjusting the confounders, women in the third quartile of LCD score might had 38\% lower chance of depression versus those in the first quartile (odds ratio $(\mathrm{OR})=0.62$, confidence interval $(\mathrm{Cl})=0.42-0.93$ ). However, no significant relationship was observed for other psychological disorders.

Conclusions: More adherences to LCD might be associated with lower chance of depression only among women. Further studies special prospective studies are required to validate these results.

Keywords: Diet, Psychological disorders, Low carbohydrate diet

\section{Introduction}

Depression, anxiety, and stress are among the most common psychological disorders in the world $[1,2]$ and are one of the important risk factors of stroke, cardiovascular disease (CVD), and some cancers [3, 4]. The prevalence of depression and anxiety has been reported as 4.4 and $3.6 \%$ in the worldwide respectively [5], whereas the

*Correspondence: hoseinzade.mahdie@gmail.com

${ }^{1}$ Nutrition and Food Security Research Center, Shahid Sadoughi University of Medical Sciences, Yazd, Iran

Full list of author information is available at the end of the article prevalence rates of anxiety and depression among Iranian adults were estimated as 21.0 and $20.8 \%$ respectively [6].

Diet as a modifiable factor can affect psychological health. However, most previous studies regarding dietary factors and psychological disorders have been focused on individual macronutrients rather than their combination. For example, the results of a prospective study showed that high intakes of protein had a protective effect on depressive symptoms [7]. Low protein intakes were also associated with increased risk of psychological disorders in a cross-sectional research among Japanese male workers [8]. Furthermore, low carbohydrate along with high protein and fat original author(s) and the source, provide a link to the Creative Commons licence, and indicate if changes were made. The images or other third party material in this article are included in the article's Creative Commons licence, unless indicated otherwise in a credit line to the material. If material is not included in the article's Creative Commons licence and your intended use is not permitted by statutory regulation or exceeds the permitted use, you will need to obtain permission directly from the copyright holder. To view a copy of this licence, visit http://creativecommons.org/licenses/by/4.0/. The Creative Commons Public Domain Dedication waiver (http://creativeco mmons.org/publicdomain/zero/1.0/) applies to the data made available in this article, unless otherwise stated in a credit line to the data. 
consumptions were resulted in higher satiety and better mood [9]. Higher dietary glycemic index was also related to higher chance of psychiatric disorders [10, 11 .

Carbohydrates are the main source of energy in the diet of Asian populations [12]. Several studies on Asian populations such as Koreans [13, 14], Japanese [15], and Chinese $[16,17]$ found that a high carbohydrate diet or more consumption of white rice was related to increasing risk of disease such as type 2 diabetes, metabolic syndrome and cardiovascular disease. Moreover, evidence has been shown that fat consumption among Asian populations such as Koreans and Japanese was lower than Western populations [12]. One cross-sectional study among Korean adults also indicated that a very low fat diet could increase risk of disease such as metabolic syndrome [18]. Thus, available evidence demonstrates that a high carbohydrate low fat diet may have a main role in the progression and management of disease specially in Asian countries [12].

Low carbohydrate diet (LCD) score is a newly suggested approach of macronutrient diet scores which can provide a comprehensive approach to diet-disease associations and can be more suitable to explanation of related diet and risk of chronic diseases [19, 20]. LCD considers the proportion of all dietary macronutrients in the form of a dietary pattern and defined as a diet with lower intakes of carbohydrates and higher intakes of proteins and fats [21-23].

Several studies were performed regarding relation between LCD and risk of chronic disease such metabolic syndrome [12, 24, 25], diabetes [19, 26], cardiovascular disease [20,27], and cancer [28, 29]. Nevertheless, a few studies especially large scale studies have been evaluated association between LCD and psychological disorders and their findings were inconsistence [23, 30-33]. One research did not find any significant association between LCD score and psychological disorders (depression, anxiety and psychological distress) in a sample of Iranian adults [23], while the findings of other studies indicated a protective effect of this dietary pattern on depression in diabetic women [30] and overweight or obese women [31, 32]. More adherence to LCD was also associated with reduced chance of anxiety among diabetic women [30], overweight or obese women [32] and as well as stress in a sample of Iranian nurses [33].

Thus, regarding the important role of dietary intakes in the prevention and management of psychiatric disorders and little evidence linking LCD and these problems, the current cross-sectional study was performed to evaluate relationship between LCD score and psychological disorders including depression, anxiety and stress among a large representative sample of Iranian adult population.

\section{Materials and methods}

\section{Study population and data collection}

In the present cross sectional analysis, data from the recruitment phase of Yazd Health Study (YaHS) and Taghzieh Mardom-e-Yazd (TAMIZ) Study were used. YaHS is a population-based cohort study which has been conducted a large population of residents (2069 years old) in Yazd city. Adults $(n=10,000)$ from 200 clusters were randomly selected from Yazd population according to residential postal codes using cluster sampling method. Yazd Nutrition Survey, locally known as TAMYZ in Persian, has assessed dietary and supplements intakes of participants of YaHS using a validated food frequency questionnaire (FFQ). More details of the mentioned studies have been published elsewhere [34]. The research was approved via the Ethics Committee of Shahid Sadoughi University of Medical Sciences, Yazd, Iran (Ethical approval code: IR.SSU.SPH.REC.1399.147, Date: September 16, 2020). Moreover, written informed consents were taken from all subjects. Information on socio-demographic characteristics, tobacco use, history of chronic disease, psychological health and physical activity assessments and dietary evaluation was obtained by a validated questionnaire. Furthermore, anthropometric assessments were conducted. In the present research, subjects with following exclusion criteria were excluded: having under or over estimation (total daily energy intake less than 800 or higher than $6500 \mathrm{kcal}$ ), pregnancy, following a special diet, having history of chronic disease such as CVD, diabetes, and cancer. Finally, 7165 participants were entered in the current study.

\section{Dietary assessment}

Dietary intakes assessment was conducted using a validated FFQ consisting of 178 food items which was modified version of a previously validated 168-item FFQ. Additional 10 questions relating to the consumed Yazdspecific food items were added to the original 168-item FFQ [34, 35]. Frequency and usual amount of food items consumption were asked by participants and finally amounts of intakes were converted to grams using guidelines of household scales [36].

\section{Computing the LCD score}

For calculation of LCD score, first the participants were classified according to decile of percentages of energy from carbohydrates, proteins, and fats. For carbohydrate consumption, subjects in the lowest decile received a score of 10 , adults in second decile received a score of 9 and so on down to individuals in the highest decile received a score of 1 . For consuming fat and protein, assigning the scores to deciles was reversed; so that subjects in the highest decile received a score of 10 and those 
in the lowest decile received a score of 1 . To obtain low carbohydrate diet score, the assigned points to all macronutrients were summed up which ranged from 3 to 30 and the higher score showed more adherence to LCD dietary pattern. Finally, participants were categorized according to quartiles of LCD score.

\section{Psychological health assessment}

Psychological health assessment was conducted via the Iranian validated short version of depression, anxiety and stress scale questionnaire (DASS 24 items) [37]. DASS 21 is a short form of the self-report depression, anxiety and stress scale questionnaire (DASS 24 items) with seven items per subscale. Responders read statements about these subscales and recorded their responses according to a 4-point Likert-type scale ranging from 0 (Did not apply to me at all) to 3 (Applied to me very much or most of the time). The scores were summed for identified items for each scale. As the DASS 21 was a short version of DASS (the Long Form has 42 items), the final score of each scale was multiplied by two. Eventually, definitions of depression, anxiety and stress were as follow respectively: having the score of $\geq 10$, score of $\geq 8$ and score of $\geq 15$.

\section{Anthropometric measurements}

Weight was measured by Omron BF511 portable digital scale with accuracy of $0.1 \mathrm{~kg}$. Height was measured in a standing position via a tape measure on a straight wall to the nearest centimeter based on standard method. Body Mass Index (BMI) was also obtained by dividing the body weight $(\mathrm{kg})$ by the square of height $(\mathrm{m})$.

\section{Physical activity assessment}

Physical activity assessment was performed by the Persian translation of short form of the International Physical Activity Questionnaire (IPAQ). Finally, physical activity level was presented as Metabolic Equivalent $(\mathrm{MET}) / \mathrm{min} /$ week. Physical activity can be computed by weighting each type of activity by its energy requirements defined in the metabolic equivalent of task (MET). MET is a ratio of activity metabolic rate relative to resting metabolic rate [38, 39].

\section{Statistical analysis}

Statistical analysis was performed using Statistical Package for Social Sciences (SPSS Corp,

version 18 , Chicago, IL, USA). The normality of data was evaluated by Kolmogorov-Smirnov test. For description of data, frequency and percent or mean and standard deviation were used. Comparing characteristics of participants for categorical and continuous variables were performed by chi-square or Kruskal-Wallis tests respectively according to the categories of LCD score. Assessing relation between adherence to LCD with psychological disorders (depression, anxiety, and stress) among all participants and separately in men and women was conducted by logistic regression analysis in different models. In the first model, we controlled for age (20-29, 30-39, 40-49, 50-59, 60-69 years); sex (male/female); and total energy intake (Continues, kcal/day). Second model was model 1 plus additional adjustment for history of chronic disease (hypercholesterolemia, brain disease, asthma, thyroid disorders, depression, alzheimer, blood coagulation disorders, arthritis, osteoporosis; yes/no); marital status (single, married, widowed or divorced); education level (lower than high school, high school, diploma and associated diploma, bachelors, masters and Ph.D.); smoking status (never smoker, current smoker, ex-smoker); physical activity level (continues, MET/min/ week); pregnancy or lactation (yes/no); dietary intakes of Eicosapentaenoic acid (EPA), Docosahexaenoic acid (DHA), and fiber (continues, g/day). Model 3 was model 2 plus additional adjustment for BMI (continues $\mathrm{kg} /$ $\mathrm{m}^{2}$ ). The confounding factors were chosen according to previous researches $[5,23,30]$. $P$ for trend was also estimated by considering LCD scores as continues variables in logistic regression analysis. Furthermore, we evaluated relation between LCD score as continues variable and psychological disorders using linear regression analysis. Statistical significant level was considered as p-values less than 0.05 .

\section{Results}

\section{General characteristics of study population}

General characteristics among all participants and according to the quartiles of LCD score have been indicated in Table 1. Among all participants, most of the subjects were aged $40-49$ years $(21.70 \%)$, male $(50.40 \%)$, with diploma and associated diploma education (30.90\%), never smoker $(87.60 \%)$, and married $(84.90 \%)$. Moreover, the prevalence of depression, anxiety and stress were as $8.1 \%, 10.5 \%$ and $3.3 \%$ respectively. The median BMI and physical activity level were $26.71(23.50-30.02)$ and 719.75 (229.5-1222.68). No significant difference was observed in terms of general characteristics among participants based on the quartiles of LCD score ( $\mathrm{P}^{>} 0.05$ for all).

\section{Dietary intakes among participants}

Table 2 shows dietary intakes among all participants and according to the quartiles of LCD score. It was found that all dietary intakes except fiber had significant differences between participants according to the quartiles of LCD score. The subjects in the higher quartile of LCD score had higher daily consumptions of energy, proteins, fats, 
Table 1 General characteristics of participants according to quartiles of low carbohydrate diet score

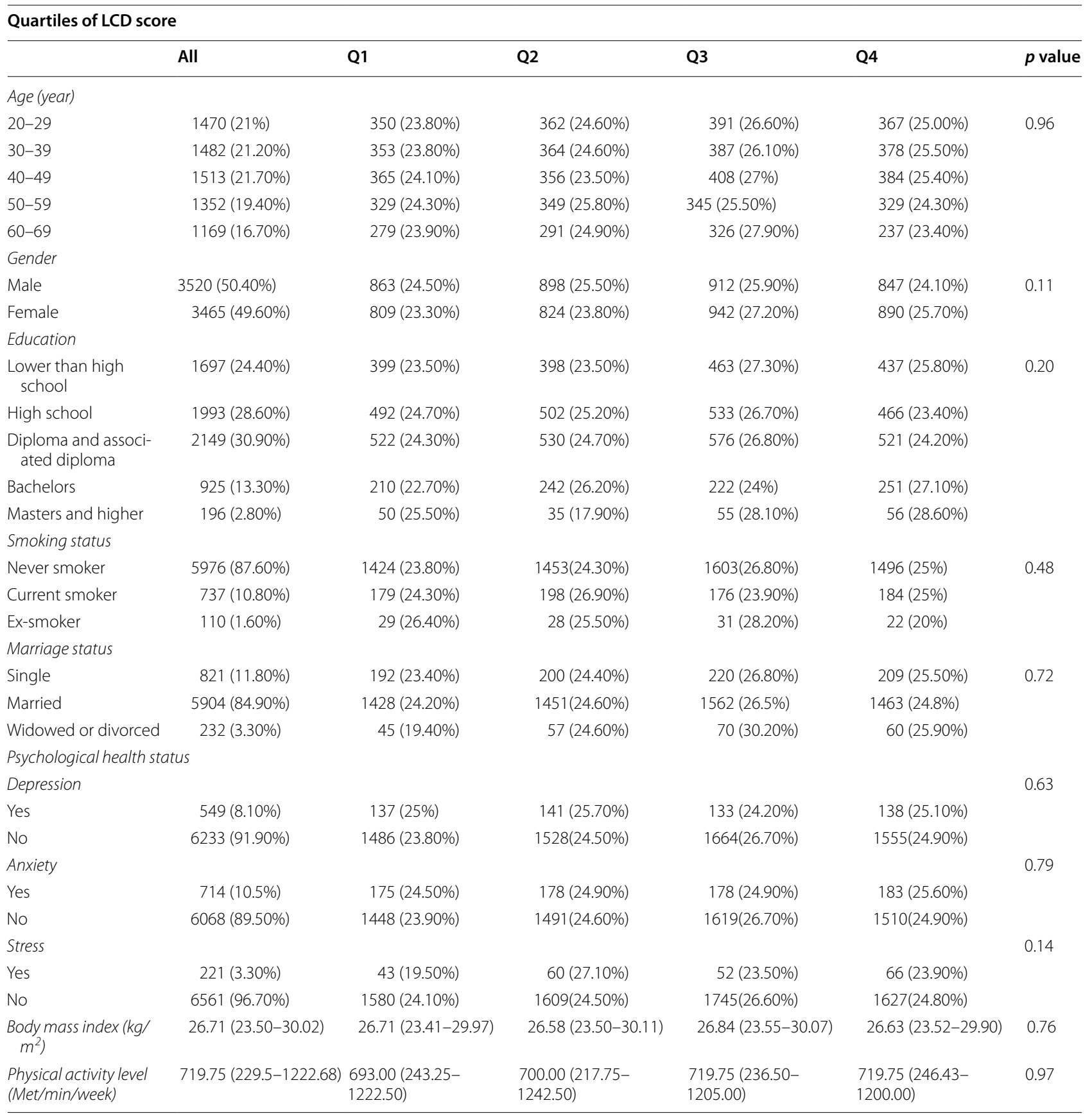

Data was presented as $\mathrm{n}(\%)$ for categorical variables or median and interquartile range (IQR) for continues variables

Comparisons were performed using chi-square or Kruskal-Wallis tests for categorical and continues variables respectively

refined grains, vegetables, legumes, dairy products, red meat, poultry, fish, eggs, nuts, EPA plus DHA than those in the lower quartile $(p<0.05$ for all). However, individuals in the higher quartile of LCD score consumed lower amounts of carbohydrates, whole grains, and fruits versus those in the lower quartile ( $p<0.05$ for all).

\section{LCD score and depression}

The results of assessing relation between LCD score and depression has been shown in Table 3. In first model, after adjusting the confounders including age (20-29, 30-39, 40-49, 50-59, 60-69 years); sex (male/ female); and total energy intake (Continues, kcal/day), 
Table 2 Dietary intakes of participants according to quartiles of low carbohydrate diet score

\begin{tabular}{|c|c|c|c|c|c|c|}
\hline \multicolumn{7}{|c|}{ Quartiles of LCD score } \\
\hline${ }^{*}$ Dietary intakes & All & Q1 & Q2 & Q3 & Q4 & ${ }^{* *} p$ value \\
\hline Total energy (kcal/d) & $\begin{array}{l}2388.48(1822.97- \\
3478.91)\end{array}$ & $\begin{array}{l}2379.36(1842.89- \\
3519.02)\end{array}$ & $\begin{array}{l}2237.46(1754.81- \\
3390.99)\end{array}$ & $\begin{array}{l}2335.54(1817.02- \\
3389.74)\end{array}$ & $\begin{array}{l}2712.62(1911.41- \\
3551.04)\end{array}$ & ${ }^{* *} p<0.0001$ \\
\hline Carbohydrates (g/d) & \multicolumn{3}{|c|}{$330.06(252.13-473.02) 387.59$ (291.65-597.21) $325.34(255.27-499.47)$} & \multicolumn{3}{|c|}{ ) $314.54(245.25-451.10) 303.06(217.25-398.10)^{* *} p<0.0001$} \\
\hline Proteins $(\mathrm{g} / \mathrm{d})$ & $95.31(72.20-132.21)$ & $79.37(62.61-106.84)$ & $88.26(69.02-117.67)$ & $97.89(77.28-130.62)$ & \multicolumn{2}{|c|}{$126.34(90.50-173.52)^{* *} p<0.000$} \\
\hline Fats $(g / d)$ & $82.94(59.45-136.06)$ & $64.45(50.67-97.47)$ & $73.16(55.76-126.76)$ & $88.98(65.14-139.39)$ & \multicolumn{2}{|c|}{ ) $115.73(77.75-160.18)^{* *} p<0.0001$} \\
\hline EPA plus DHA (g/d) & $0.04(0.01-0.08)$ & $0.04(0.01-0.08)$ & $0.04(0.01-0.08)$ & $0.04(0.01-0.09)$ & \multicolumn{2}{|c|}{$0.04(0.01-0.09) \quad{ }^{* *} p<0.0001$} \\
\hline Fiber $(g / d)$ & $3.14(2.17-4.94)$ & $3.23(2.15-5.35)$ & $3.11(2.19-4.98)$ & $3.13(2.18-4.75)$ & \multicolumn{2}{|r|}{0.08} \\
\hline Whole grains (g/d) & $59.93(26.18-92.56)$ & $84.70(27.79-115.89)$ & $73.83(27.40-95.60)$ & $52.69(24.02-90.66)$ & \multicolumn{2}{|c|}{ 06) $\stackrel{* *}{*} p<0.0001$} \\
\hline Refined grains (g/d) & \multicolumn{2}{|c|}{$\begin{array}{c}177.63(113.10-288.20) 227.41(122.21- \\
302.35)\end{array}$} & $\begin{array}{l}185.58(108.006- \\
295.25)\end{array}$ & $\begin{array}{l}172.68(116.35- \\
276.19)\end{array}$ & $\begin{array}{l}164.12(101.80- \\
274.20)\end{array}$ & ${ }^{* *} p<0.0001$ \\
\hline Vegetables (g/d) & \multicolumn{2}{|c|}{$154.04(104.69-251.41) \quad 146.26(96.09-2$} & $148.20(104.45-234.37)$ & $158.44(109.83-254.73)$ & $\begin{array}{l}169.54(106.01- \\
269.68)\end{array}$ & ${ }^{* *} p<0.0001$ \\
\hline Fruits (g/d) & \multicolumn{2}{|c|}{$\begin{array}{c}427.33(276.69-711.21) 507.68(318.87- \\
890.91)\end{array}$} & \multicolumn{2}{|c|}{418.26 (288.34-664.63) 410.88 (260.9-647.18) } & \multicolumn{2}{|c|}{$390.09(236.33-674.86)^{* *} p<0.0001$} \\
\hline Legumes (g/d) & $32.36(22.08-50.85)$ & $26.87(19.72-41.27)$ & $32.47(22.61-50.69)$ & $34.56(23.14-52.16)$ & $34.62(23.83-55.50)$ & ${ }^{* *} p<0.0001$ \\
\hline Dairy products (g/d) & $\begin{array}{l}189.77(125.34- \\
294.88)\end{array}$ & $\begin{array}{l}167.64(109.39- \\
261.004)\end{array}$ & $\begin{array}{l}187.34(123.21- \\
284.64)\end{array}$ & $\begin{array}{l}198.16(131.94- \\
303.43)\end{array}$ & $\begin{array}{l}205.10(137.24- \\
\quad 333.76)\end{array}$ & ${ }^{* *} p<0.0001$ \\
\hline Red meat (g/d) & $38.55(20.007-64.40)$ & $29.60(12.44-53.42)$ & $34.58(17.60-61.04)$ & $42.86(24.39-66.68)$ & $61.04(33.00-99.06)$ & ${ }^{* *} p<0.0001$ \\
\hline Poultry (g/d) & $27.30(15.43-74.87)$ & $24.61(13.65-39.17)$ & $27.30(14.69-51.04)$ & $39.17(15.43-74.78)$ & 74.78 (27.30-145.99) & ${ }^{* *} p<0.0001$ \\
\hline Fish $(g / d)$ & $9.38(3.45-19.34)$ & $5.67(2.38-13.73)$ & $7.20(3.45-15.21)$ & $9.98(5.63-22.55)$ & $9.98(3.65-23.62)$ & ${ }^{* *} p<0.0001$ \\
\hline Eggs (g/d) & $17.16(8.04-51.48)$ & $17.16(4.02-25.74)$ & $17.16(8.04-47.16)$ & $17.16(8.04-51.48)$ & $25.74(8.58-51.48)$ & ${ }^{* *} p<0.0001$ \\
\hline Nuts (g/d) & $12.05(6.27-23.11)$ & $9.59(5.44-16.02)$ & $12.22(6.34-23.82)$ & $12.80(6.82-29.95)$ & $12.11(6.40-27.31)$ & ${ }^{* *} p<0.0001$ \\
\hline
\end{tabular}

* Data was presented as median and interquartile range (IQR). ${ }^{* *}$ Comparisons were performed using Kruskal-Wallis test

no significant association was observed between LCD score and depression in all participants (forth quartile versus first quartile: odds ratio $(\mathrm{OR})=0.96$, confidence interval $(\mathrm{CI})=0.74-1.22$ ) and men (forth quartile versus first quartile: $\mathrm{OR}=0.85, \mathrm{CI}=0.58-1.24)$. Similarly, additional adjustments for history of chronic disease (hypercholesterolemia, asthma, thyroid disorders, depression, alzheimer, blood coagulation disorders, arthritis, osteoporosis; yes/no; yes/no); marital status (single, married, widowed or divorced); education level (lower than high school, high school, diploma and associated diploma, bachelors, masters and Ph.D.); smoking status (never smoker, current smoker, ex-smoker); physical activity level (continues, MET/min/week); dietary intakes of EPA plus DHA; fiber (all: forth quartile versus first quartile: $\mathrm{OR}=0.98, \mathrm{CI}=0.75-1.28$; men: forth quartile versus first quartile: $O R=0.82$, $\mathrm{CI}=0.55-1.23$ ) and BMI (all: forth quartile versus first quartile: $\mathrm{OR}=0.96, \mathrm{CI}=0.73-1.25$; men: forth quartile versus first quartile: $\mathrm{OR}=0.79, \mathrm{CI}=0.53-1.20$ ) showed no significant relation between LCD score and depression in second and third models. No significant trend was also found in chance of depression across quartiles of LCD scores in all models among all subjects and men $(p>0.05)$.
However, after adjusting in model 1, a significant inverse association was detected between LCD and depression in the third quartile of LCD score than the first quartile among women $(\mathrm{OR}=0.61, \mathrm{CI}=0.42-0.88)$. This relationship did not change after additional adjusting in the models $2(\mathrm{OR}=0.64, \mathrm{CI}=0.43-0.94)$ and 3 $(\mathrm{OR}=0.62, \mathrm{CI}=0.42-0.93)$. No significant trend was also observed in odds of depression across quartiles of LCD scores in all models in women $(p>0.05)$.

Moreover, in linear regression analysis, no significant association was discovered between LCD score and depression in all participants and separately in men and women (supplementary table).

\section{LCD score and anxiety}

Table 3 shows the findings of evaluating association between LCD score and anxiety. It was observed that there was no significant relation between LCD score and anxiety in all participants (forth quartile versus first quartile: $\mathrm{OR}=1.007, \mathrm{CI}=0.79-1.27$ ) and men (forth quartile versus first quartile: $\mathrm{OR}=0.83, \mathrm{CI}=0.58-1.18$ ) after adjustment for the confounders. No significant trend was also observed in chance of anxiety across quartiles of LCD scores in all models in all individuals and men $(p>0.05)$. Although, a significant inverse association was 
Table 3 Multivariable-adjusted odds ratio (OR) for psychological disorders across quartiles low-carbohydrate diet (LCD) score

\begin{tabular}{|c|c|c|c|c|c|}
\hline \multirow[t]{2}{*}{ Quartiles of LCD score } & \multirow{2}{*}{$\begin{array}{l}\text { Q1 } \\
\text { OR (Cl) }\end{array}$} & \multirow{2}{*}{$\begin{array}{l}\text { Q2 } \\
\text { OR (Cl) }\end{array}$} & \multirow{2}{*}{$\begin{array}{l}\text { Q3 } \\
\text { OR (Cl) }\end{array}$} & \multirow{2}{*}{$\begin{array}{l}\text { Q4 } \\
\text { OR (Cl) }\end{array}$} & \multirow[t]{2}{*}{ P-trend } \\
\hline & & & & & \\
\hline \multicolumn{6}{|l|}{ Depression } \\
\hline \multicolumn{6}{|l|}{ Model 1} \\
\hline All & Reference & $0.98(0.77-1.26)$ & $0.86(0.67-1.10)$ & $0.96(0.74-1.22)$ & 0.51 \\
\hline Men & Reference & $0.92(0.64-1.32)$ & $1.16(0.82-1.64)$ & $0.85(0.58-1.24)$ & 0.74 \\
\hline women & Reference & $1.04(0.74-1.45)$ & $0.61(0.42-0.88)^{*}$ & $1.04(0.74-1.45)$ & 0.53 \\
\hline \multicolumn{6}{|l|}{ Model 2} \\
\hline All & Reference & $0.96(0.74-1.26)$ & $0.89(0.68-1.16)$ & $0.98(0.75-1.28)$ & 0.75 \\
\hline Men & Reference & $0.85(0.58-1.27)$ & $1.18(0.82-1.71)$ & $0.82(0.55-1.23)$ & 0.77 \\
\hline women & Reference & $1.06(0.74-1.54)$ & $0.64(0.43-0.94)^{*}$ & $1.10(0.77-1.58)$ & 0.82 \\
\hline \multicolumn{6}{|l|}{ Model 3} \\
\hline All & Reference & $0.95(0.73-1.24)$ & $0.87(0.66-1.14)$ & $0.96(0.73-1.25)$ & 0.62 \\
\hline Men & Reference & $0.85(0.58-1.26)$ & $1.16(0.80-1.68)$ & $0.79(0.53-1.20)$ & 0.64 \\
\hline women & Reference & $1.04(0.72-1.50)$ & $0.62(0.42-0.93)^{*}$ & $1.08(0.75-1.54)$ & 0.75 \\
\hline \multicolumn{6}{|l|}{ Anxiety } \\
\hline \multicolumn{6}{|l|}{ Model 1} \\
\hline All & Reference & $0.98(0.78-1.22)$ & $0.91(0.73-1.13)$ & $1.004(0.80-1.25)$ & 0.86 \\
\hline Men & Reference & $0.90(0.65-1.23)$ & $1.14(0.84-1.54)$ & $0.90(0.65-1.24)$ & 0.96 \\
\hline women & Reference & $1.06(0.78-1.45)$ & $0.69(0.49-0.96)^{*}$ & $1.09(0.80-1.48)$ & 0.82 \\
\hline \multicolumn{6}{|l|}{ Model 2} \\
\hline All & Reference & $0.93(0.73-1.18)$ & $0.91(0.71-1.15)$ & $1.003(0.79-1.27)$ & 0.98 \\
\hline Men & Reference & $0.81(0.58-1.15)$ & $1.11(0.80-1.53)$ & $0.83(0.58-1.17)$ & 0.70 \\
\hline women & Reference & $1.05(0.75-1.48)$ & $0.71(0.50-1.02)$ & $1.16(0.83-1.62)$ & 0.77 \\
\hline \multicolumn{6}{|l|}{ Model 3} \\
\hline All & Reference & $0.93(0.73-1.19)$ & $0.91(0.72-1.16)$ & $1.007(0.79-1.27)$ & 0.98 \\
\hline Men & Reference & $0.82(0.58-1.16)$ & $1.12(0.81-1.55)$ & $0.83(0.58-1.18)$ & 0.72 \\
\hline Women & Reference & $1.04(0.74-1.47)$ & $0.71(0.50-1.02)$ & $1.16(0.83-1.62)$ & 0.77 \\
\hline \multicolumn{6}{|l|}{ Stress } \\
\hline \multicolumn{6}{|l|}{ Model 1} \\
\hline All & Reference & $1.33(0.89-1.98)$ & $1.07(0.71-1.62)$ & $1.45(0.99-2.18)$ & 0.13 \\
\hline Men & Reference & $1.36(0.74-2.50)$ & $1.34(0.73-2.74)$ & $1.40(0.76-2.60)$ & 0.32 \\
\hline Women & Reference & $1.29(0.76-2.20)$ & $0.88(0.50-1.54)$ & $1.50(0.90-2.50)$ & 0.26 \\
\hline \multicolumn{6}{|l|}{ Model 2} \\
\hline All & Reference & $1.13(0.73-1.74)$ & $1.01(0.65-1.56)$ & $1.42(0.94-2.15)$ & 0.13 \\
\hline Men & Reference & $1.16(0.60-2.26)$ & $1.36(0.71-2.59)$ & $1.42(0.73-2.73)$ & 0.24 \\
\hline Women & Reference & $1.12(0.63-1.98)$ & $0.78(0.43-1.41)$ & $1.42(0.83-2.45)$ & 0.34 \\
\hline \multicolumn{6}{|l|}{ Model 3} \\
\hline All & Reference & $1.12(0.72-1.72)$ & $0.98(0.63-1.52$ & $1.38(0.91-2.10)$ & 0.18 \\
\hline Men & Reference & $1.12(0.58-2.18)$ & $1.27(0.66-2.43)$ & $1.30(0.67-2.52)$ & 0.38 \\
\hline Women & Reference & $1.11(0.62-1.96)$ & $0.78(0.43-1.41)$ & $1.42(0.82-2.44)$ & 0.34 \\
\hline
\end{tabular}

Cl: confidence interval

Model 1: Adjusted for sex (male/female); age (20-29, 30-39, 40-49, 50-59, 60-69); and total energy intake (continues, kcal/day)

Model 2: Model 1 + history of chronic disease (yes/no);; marital status (single, married, widow or discovered); education level (lower than high school, high school, Diploma and associated diploma, Bachelors, Masters and higher); smoking history (never smoker, current smoker, ex-smoker); physical activity level (MET/min/week); pregnancy or lactation (yes/no); intakes of dietary EPA, DHA, and fiber (continues, $\mathrm{g} / \mathrm{d}$ )

Model 3: Model $2+$ body mass index (BMI) (continues, $\mathrm{kg} / \mathrm{m}^{2}$ )

$p<0.05$ was considered as a significance level 
found between LCD and anxiety in the third quartile of LCD score in comparison to the first quartile among women after adjusting for age, sex, and total energy intake (third quartile versus first quartile: $O R=0.69$, $\mathrm{CI}=0.49-0.96$ ), no significant relationship was observed after further adjustment for other confounders in models 2 (third quartile versus first quartile: $O R=0.71$, $\mathrm{CI}=0.50-1.02$ ) and 3 (third quartile versus first quartile: $\mathrm{OR}=0.71, \mathrm{CI}=0.50-1.02)$. No significant trend was also found in odds of anxiety across quartiles of LCD scores in all models in women $(p>0.05)$.

Furthermore, in linear regression analysis, no significant relationship was detected between LCD score and anxiety in all participants and separately in men and women (supplementary table).

\section{LCD score and stress}

The results of assessing association between LCD score and stress has been presented in Table 3. According to the results, no significant relation was discovered between LCD score and stress in all participants (forth quartile versus first quartile: $\mathrm{OR}=1.38, \mathrm{CI}=0.91-2.10$ ) and separately in men (forth quartile versus first quartile: $\mathrm{OR}=1.30, \mathrm{CI}=0.67-2.52$ ) and women (forth quartile versus first quartile: $\mathrm{OR}=1.42, \mathrm{CI}=0.82-2.44$ ) after adjustment for all confounders.

No significant trend was also observed in chance of stress across quartiles of LCD scores in all models in all individuals and separately in men and women $(p>0.05)$.

In addition, in linear regression analysis, no significant association was found between LCD score and stress in all participants and separately in men and women (Additional file 1: Supplementary table).

\section{Discussion}

This research demonstrated no significant association between LCD score and psychological disorders in all participants or men. Although, a significant inverse association was observed between LCD score and anxiety among women after adjustment for age, sex, and total energy intake, this relation was not significant after additional adjustment for other confounders. Furthermore, more adherences to LCD might be related to reduce chance of depression in women after adjusting all confounders.

Earlier studies had mostly focused on individual dietary macronutrients rather than their combination. In line with our results, one survey reported no significant association between carbohydrates or fats consumption with depression among Japanese men [8]. Furthermore, high carbohydrates consumption was associated with lower risk of anxiety and depression in obese women [40]. An inverse relation was also found between consuming high carbohydrates and high proteins with depression [41]. A few studies have been assessed relation between LCD and psychiatric disorders [23, 30-33]. Similar to our study, more adherence to LCD was related to lower risk of depression among women with type 2 diabetes [30] and overweight or obese women [31, 32]. In contrary to our findings, Ebrahimpour-Koujan et al., observed no relationship between LCD score and psychological disorders in a sample of Iranian adults [23]. Moreover, a significant association was reported between higher LCD score and decreased chance of anxiety in diabetic women [30] and overweight or obese women [32] in other studies. A protective role of LCD was also observed against stress in overweight or obese women [32] and a sample of Iranian nurses [33]. Discrepancies between others and ours might be related to differences in sample size, characteristics and health status of participants, and as well as psychological health assessment tool, and as well as computing LCD score.

Exact mechanisms regarding LCD and psychological disorders are still unknown. Nevertheless, foods containing high proteins can cause more sense of fullness and less tiredness versus foods containing high carbohydrates [42, 43]. A high refined carbohydrate diet resulted in developing depressive behaviors and anxiety in an animal study [44]. Moreover, diet rich in protein contains high amounts of amino acids including tryptophan as precursors of neurotransmitters such as serotonin that can have preventive role against psychiatric distress [33]. According to the results of Lucas et al., dietary patterns containing refined carbohydrates, sweet desserts, and sugar were related to higher risk of psychiatric disorders especially depression in women by increasing levels of inflammatory cytokines such as IL-6 and CRP [45]. In addition, It has been found that low glycemic index diet was related to decreased risk of insulin resistance and consequently reduced risk of cognitive and psychological disorders [11]. One clinical trial found that LCD had better effects on mood in compared with other restricted calorie diets after 12 months [46]. Evidence has demonstrated that LCD can inhibit glutamate decarboxylase and led to stimulating the synthesis of gamma-aminobutyric acid and eventually results in the anxiolytic/antidepressant effects $[47,48]$. According to animal studies, LCD was associated with anti-inflammatory effects and increased brain-derived neurotrophic factor levels in brain that this impact might contribute to protective role against psychology disorders [48-50]. Furthermore, LCD may be effective as a mood stabilizer in depressive disorders [51]. A recent survey also suggested a possible relationship between low carbohydrate diet and depression by the mediatory role of adipokines in overweight or obese [31]. 
To best of our knowledge, the current research is the first population-based study regarding association between LCD and psychological disorders. FFQs were completed by a trained expert. Analyzes linking evaluation of relation between LCD and psychological disorders were also stratified by sex. Furthermore, we controlled for a wide range of confounders that might affect the psychological status of subjects. However, this study suffered from some limitations. This research cannot accurately explain the causal association among the study variables due to cross sectional nature. Although we applied valid and reliable questionnaires for evaluation of the variables such as dietary intakes, psychological health status and physical activity, some measurement bias cannot be completely avoided. In addition, we could not control the impact of all confounding factors because of unknown or unmeasured factors.

Although dietary pattern approach can provide a comprehensive insight into diet-disease associations and account complex interactions among individual foods and nutrients, the significant results in women could be from chance and they should be stated with caution due to complexity of dietary nutrition and health outcomes and as well as cross sectional design of the study.

\section{Conclusion}

Our study did not indicate any significant relationship between LCD score and psychological disorders among all participants and men. Although, a significant inverse relation was discovered between LCD score and anxiety in women after adjustment for age, sex, and total energy intake, this association was not significant after additional adjustment for other confounders. Moreover, LCD might be associated with decreased chance of depression in women after adjusting all confounders. Further researches especially population-based longitude studies are recommended to present more conclusive evidence to clarify relation between LCD and psychological disorders.

\section{Supplementary Information}

The online version contains supplementary material available at https://doi. org/10.1186/s12986-021-00546-3.

Additional file 1: Supplementary Table. Linear regression model for relation between psychological disorders and low-carbohydrate diet (LCD) score.

\section{Abbreviations}

LCD: Iow carbohydrate diet; YaHS: Yazd Health Study; TAMIZ: Taghzieh Mardom-e-Yazd; DASS 21: short version of depression, anxiety and stress scale questionnaire; OR: odds ratio; Cl: confidence interval; CVD: cardiovascular disease; FFQ: food frequency questionnaire; BMI: Body Mass Index; IPAQ: International Physical Activity Questionnaire; MET: metabolic equivalent.

\section{Acknowledgements}

The authors thank Nutrition and Food Security Research Center, Shahid Sadoughi University of Medical Sciences, Yazd, Iran to support this study.

\section{Authors' contributions}

M. H, A. S-A, and M. M designed the study. Z. S. S and Z. S. S conducted the statistical analysis. Z. S. S and Z. S. S wrote the draft of manuscript. M. H, A. S-A, and $M$. M critically revised the manuscript and confirmed the final version of it to submit. All authors read and approved the final version of manuscript.

\section{Funding}

This study supported by Nutrition and Food Security Research Center, Shahid Sadoughi University of Medical Sciences, Yazd, Iran (Number: 7945).

\section{Availability of data and materials}

All data generated or analyzed during this study has been included in this manuscript.

\section{Consent for publication \\ Not applicable.}

\section{Ethics approval and consent to participate}

This study was approved by the Ethics Committee of Shahid Sadoughi University of Medical Sciences, Yazd, Iran (Ethical approval code: IR.SSU. REC.1393.7341, Date: July 8, 2014). Furthermore, written informed consents were taken from all individuals.

\section{Competing interests}

The authors declare that they have no competing interests.

\section{Author details}

${ }^{1}$ Nutrition and Food Security Research Center, Shahid Sadoughi University of Medical Sciences, Yazd, Iran. ${ }^{2}$ Department of Nutrition, School of Public Health, Shahid Sadoughi University of Medical Sciences, Yazd, Iran. ${ }^{3}$ Psychiatry and Behavioral Sciences Research Center, Ibn-e-Sina Hospital, Faculty of Medicine, Mashhad University of Medical Sciences, Mashhad, Iran. ${ }^{4}$ Yazd Cardiovascular Research Centre, Shahid Sadoughi University of Medical Sciences, Yazd, Iran.

Received: 3 November 2020 Accepted: 18 January 2021

Published online: 30 January 2021

\section{References}

1. Sangsefidi ZS, Mirzaei M, Hosseinzadeh M. The relation between dietary intakes and psychological disorders in Iranian adults: a population-based study. BMC Psychiatry. 2020;20:1-9.

2. Sayers J. The world health report 2001-Mental health: new understanding, new hope. Bull World Health Organ. 2001;79:1085-1085.

3. Russ TC, Stamatakis E, Hamer M, Starr JM, Kivimäki M, Batty GD. Association between psychological distress and mortality: individual participant pooled analysis of 10 prospective cohort studies. BMJ. 2012;345:e4933.

4. Sangsefidi ZS, Lorzadeh E, Hosseinzadeh M, Mirzaei M. Dietary habits and psychological disorders in a large sample of Iranian adults: a populationbased study. Ann Gen Psychiatry. 2020;19:1-10.

5. WHO: Other common mental disorders: global health estimates. Geneva: World Health Organization 2017:1-24.

6. Noorbala AA, Yazdi SB, Yasamy M, Mohammad K. Mental health survey of the adult population in Iran. Br J Psychiatry. 2004;184:70-3.

7. Wolfe AR, Arroyo C, Tedders SH, Li Y, Dai Q, Zhang J. Dietary protein and protein-rich food in relation to severely depressed mood: a 10 year follow-up of a national cohort. Prog Neuropsychopharmacol Biol Psychiatry. 2011;35:232-8.

8. Nanri A, Eguchi M, Kuwahara K, Kochi T, Kurotani K, Ito R, Pham NM, Tsuruoka H, Akter S, Jacka F. Macronutrient intake and depressive symptoms among Japanese male workers: the Furukawa Nutrition and Health Study Psychiatry Res. 2014;220:263-8. 
9. Galletly C, Moran L, Noakes M, Clifton P, Tomlinson L, Norman R. Psychological benefits of a high-protein, low-carbohydrate diet in obese women with polycystic ovary syndrome-A pilot study. Appetite. 2007:49:590-3.

10. Gangwisch JE, Hale L, Garcia L, Malaspina D, Opler MG, Payne ME, Rossom RC, Lane D. High glycemic index diet as a risk factor for depression: analyses from the Women's Health Initiative. Am J Clin Nutr. 2015;102:454-63.

11. Haghighatdoost F, Azadbakht L, Keshteli AH, Feinle-Bisset C, Daghaghzadeh H, Afshar H, Feizi A, Esmaillzadeh A, Adibi P. Glycemic index, glycemic load, and common psychological disorders. Am J Clin Nutr. 2016;103:201-9.

12. Ha K, Joung H, Song Y. Low-carbohydrate diet and the risk of metabolic syndrome in Korean adults. Nutr Metab Cardiovasc Diseases. 2018:28:1122-32.

13. Park S-H, Lee K-S, Park H-Y. Dietary carbohydrate intake is associated with cardiovascular disease risk in Korean: analysis of the third Korea National Health and Nutrition Examination Survey (KNHANES III). Int J Cardiol. 2010;139:234-40.

14. Song S, Lee JE, Song WO, Paik H-Y, Song Y. Carbohydrate intake and refined-grain consumption are associated with metabolic syndrome in the Korean adult population. J Acad Nutr Dietetics. 2014;114:54-62.

15. Nanri A, Mizoue T, Noda M, Takahashi Y, Kato M, Inoue M, Tsugane S. Group JPHCbPS: Rice intake and type 2 diabetes in Japanese men and women: the Japan Public Health Center-based Prospective Study. Am J Clin Nutr. 2010;92:1468-77.

16. Villegas R, Liu S, Gao Y-T, Yang G, Li H, Zheng W, Shu XO. Prospective study of dietary carbohydrates, glycemic index, glycemic load, and incidence of type 2 diabetes mellitus in middle-aged Chinese women. Arch Intern Med. 2007;167:2310-6.

17. Feng R, Du S, Chen Y, Zheng S, Zhang W, Na G, Li Y, Sun C. High carbohydrate intake from starchy foods is positively associated with metabolic disorders: a Cohort Study from a Chinese population. Sci Rep. 2015;5:1-8.

18. Park S, Ahn J, Lee B-K. Very-low-fat diets may be associated with increased risk of metabolic syndrome in the adult population. Clin Nutr. 2016;35:1159-67.

19. de Koning L, Fung TT, Liao X, Chiuve SE, Rimm EB, Willett WC, Spiegelman D, Hu FB. Low-carbohydrate diet scores and risk of type 2 diabetes in men. Am J Clin Nutr. 2011;93:844-50.

20. Halton TL, Willett WC, Liu S, Manson JE, Albert CM, Rexrode K, Hu FB. Lowcarbohydrate-diet score and the risk of coronary heart disease in women N Engl J Med. 2006;355:1991-2002.

21. Hite AH, Berkowitz VG, Berkowitz K. Low-carbohydrate diet review: shifting the paradigm. Nutr Clin Pract. 2011;26:300-8.

22. Jafari-Maram S, Daneshzad E, Brett NR, Bellissimo N, Azadbakht L. Association of low-carbohydrate diet score with overweight, obesity and cardiovascular disease risk factors: a cross-sectional study in Iranian women. J Cardiovasc Thora Res. 2019;11:216.

23. Ebrahimpour-Koujan S, Keshteli AH, Afshar H, Esmaillzadeh A, Adibi P. Adherence to low carbohydrate diet and prevalence of psychological disorders in adults. Nutr J. 2019;18:87.

24. Mirmiran P, Asghari G, Farhadnejad H, Eslamian G, Hosseini-Esfahani F, Azizi F. Low carbohydrate diet is associated with reduced risk of metabolic syndrome in Tehranian adults. Int J Food Sci Nutr. 2017;68:358-65.

25. Shirani F, Esmaillzadeh A, Keshteli AH, Adibi P, Azadbakht L. Low-carbohydrate-diet score and metabolic syndrome: an epidemiologic study among Iranian women. Nutrition. 2015;31:1124-30.

26. Nanri A, Mizoue T, Kurotani K, Goto A, Oba S, Noda M, Sawada N, Tsugane S, Group JPHC-BPS: Low-carbohydrate diet and type 2 diabetes risk in Japanese men and women: the Japan Public Health Center-Based Prospective Study. PLoS ONE 2015, 10.

27. Farhadnejad H, Asghari G, Teymoori F, Tahmasebinejad Z, Mirmiran P, Azizi F. Low carbohydrate diet and cardiovascular diseases in Iranian population: Tehran Lipid and Glucose study. Metabolism and Cardiovascular Diseases: Nutrition; 2019.

28. Ho VW, Leung K, Hsu A, Luk B, Lai J, Shen SY, Minchinton Al, Waterhouse $D$, Bally MB, Lin W. A low carbohydrate, high protein diet slows tumor growth and prevents cancer initiation. Can Res. 2011;71:4484-93.

29. Sasanfar B, Toorang F, Esmaillzadeh A, Zendehdel K. Adherence to the low carbohydrate diet and the risk of breast Cancer in Iran. Nutr J. 2019;18:86.

30. Daneshzad E, Keshavarz SA, Qorbani M, Larijani B, Azadbakht L: The association between Low Carbohydrate diet, sleep status, depression, anxiety and stress score. J Sci Food Agric. 2020.
31. Imani H, Mirzaei K, Setayesh L, Pooyan S, Ebrahimi R, Yarizadeh H, Rashidbeygi E, Badrooj N: Adipokines: the possible association between low carbohydrate diet score and depression. 2020.

32. Yarizadeh H, Setayesh L, Askarpour M, Keshavarz SA, Mirzaei K. The relationship between low carbohydrate diet score and mental health in overweight and obese women. Qom Univ Med Sci J. 2020;14:47-54.

33. Dehghani A, Sanjari M, Salemi S, Maghbooli Z, Mirzaie K. Association of low-carbohydrate diet score with perceived stress score: a cross-sectional study in Iranian nurses. Koomesh. 2020;22:452-60.

34. Mirzaei M, Salehi-Abargouei A, Mirzaei M, Mohsenpour MA. Cohort Profile: The Yazd Health Study (YaHS): a population-based study of adults aged 20-70 years (study design and baseline population data). Int J Epidemiol. 2018:47:697-698h.

35. Esfahani FH, Asghari G, Mirmiran P, Azizi F. Reproducibility and relative validity of food group intake in a food frequency questionnaire developed for the Tehran Lipid and Glucose Study. J Epidemiol. 2010;20:150-8.

36. Ghafarpour M, Houshiar-Rad A, Kianfar H, Ghaffarpour M: The manual for household measures, cooking yields factors and edible portion of food. 1999.

37. Sahebi A, Asghari MJ, Salari R: Validation of depression anxiety and stress scale (DASS-21) for an Iranian population. 2005.

38. Committee IR: Guidelines for data processing and analysis of the International Physical Activity Questionnaire (IPAQ)-short and long forms. http:// www.ipaq.ki.se/scoring.pdf. 2005.

39. Moghaddam MB, Aghdam FB, Jafarabadi MA, Allahverdipour H, Nikookheslat SD, Safarpour S. The Iranian Version of International Physical Activity Questionnaire (IPAQ) in Iran: content and construct validity, factor structure, internal consistency and stability. World Appl Sci J. 2012;18:1073-80.

40. Pellegrin KL, O'Neil PM, Stellefson EJ, Fossey MD, Ballenger JC, Cochrane $\mathrm{CE}$, Currey HS. Average daily nutrient intake and mood among obese women. Nutr Res. 1998;18:1103-12.

41. de Castro JM. Macronutrient relationships with meal patterns and mood in the spontaneous feeding behavior of humans. Physiol Behav. 1987:39:561-9.

42. Paz A, Berry EM. Effect of meal composition on alertness and performance of hospital night-shift workers. Ann Nutr Metab. 1997:41:291-8.

43. Spring B, Maller O, Wurtman J, Digman L, Cozolino L. Effects of protein and carbohydrate meals on mood and performance: interactions with sex and age. J Psychiatr Res. 1982;17:155-67.

44. Santos CJ, Ferreira AV, Oliveira AL, Oliveira MC, Gomes JS, Aguiar DC. Carbohydrate-enriched diet predispose to anxiety and depression-like behavior after stress in mice. Nutr Neurosci. 2018;21:33-9.

45. Lucas M, Chocano-Bedoya P, Shulze MB, Mirzaei F, O'Reilly ÉJ, Okereke Ol, Hu FB, Willett WC, Ascherio A. Inflammatory dietary pattern and risk of depression among women. Brain Behav Immun. 2014;36:46-53.

46. Brinkworth GD, Buckley JD, Noakes M, Clifton PM, Wilson CJ. Long-term effects of a very low-carbohydrate diet and a low-fat diet on mood and cognitive function. Arch Intern Med. 2009;169:1873-80.

47. Neal EG, Cross J. Efficacy of dietary treatments for epilepsy. J Hum Nutr Diet. 2010;23:113-9.

48. Inta D, Wölnerhanssen BK, Meyer-Gerspach AC, Lang E, Schweinfurth N, Mallien AS, Vasilescu A-N, Schmidt A, Rea K, Westendorf AM: Common pathways in depression and obesity: the role of gut microbiome and diets. Curr Behav Neurosci Rep 2020:1-7.

49. Puchowicz MA, Xu K, Sun X, Ivy A, Emancipator D, LaManna JC. Dietinduced ketosis increases capillary density without altered blood flow in rat brain. Am J Physiol-Endocrinol Metab. 2007;292:E1607-15.

50. Genzer Y, Dadon M, Burg C, Chapnik N, Froy O. Effect of dietary fat and the circadian clock on the expression of brain-derived neurotrophic factor (BDNF). Mol Cell Endocrinol. 2016;430:49-55.

51. El-Mallakh R, Paskitti M. The ketogenic diet may have mood-stabilizing properties. Med Hypotheses. 2001;57:724-6.

\section{Publisher's Note}

Springer Nature remains neutral with regard to jurisdictional claims in published maps and institutional affiliations. 